\title{
South African Weather Service operational satellite based precipitation estimation technique: applications and improvements
}

\author{
E. de Coning and E. Poolman \\ South African Weather Service, Private Bag X097, Pretoria, 0001, South Africa \\ Received: 8 November 2010 - Published in Hydrol. Earth Syst. Sci. Discuss.: 12 November 2010 \\ Revised: 22 February 2011 - Accepted: 25 March 2011 - Published: 6 April 2011
}

\begin{abstract}
Extreme weather related to heavy or more frequent precipitation events seem to be a likely possibility for the future of our planet. While precipitation measurements can be done by means of rain gauges, the obvious disadvantages of point measurements are driving meteorologists towards remotely sensed precipitation methods. In South Africa more sophisticated and expensive nowcasting technology such as radar and lightning networks are available, supported by a fairly dense rain gauge network of about 1500 daily gauges. In the rest of southern Africa rainfall measurements are more difficult to obtain. The local version of the Unified Model and the Meteosat Second Generation satellite data are ideal components of precipitation estimation in data sparse regions such as Africa. In South Africa hourly accumulations of the Hydroestimator (originally from NOAA/NESDIS) are currently used as a satellite based precipitation estimator for the South African Flash Flood Guidance system, especially in regions which are not covered by radar. In this study the Hydroestimator and the stratiform rainfall field from the Unified Model are both bias corrected and then combined into a new precipitation field. The new product was tested over a two year period and provides a more accurate and comprehensive input to the Flash Flood Guidance systems in the data sparse southern Africa. Future work will include updating the period over which bias corrections were calculated.
\end{abstract}

\section{Introduction}

There is mounting evidence that changes in the earth's climate system will result in more frequent extreme weather events and an increased likelihood of temperature extremes,

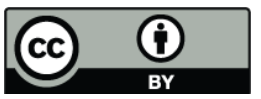

Correspondence to: E. de Coning (estelle.deconing@weathersa.co.za) heat waves, and heavy precipitation events (IPCC, 2007). The importance of early warning systems to warn the public of these types of weather events therefore becomes more and more critical.

When forecasters have to issue forecasts and warnings for the first 12 hours of a forecast, they use the latest data from remote sensing tools such as radar and satellite, as well as observational data, to analyze and forecast smaller scale weather features. The World Meteorological Organisation (WMO) organized a series of sub-regional demonstration projects to improve severe weather forecast services in countries where sophisticated remote sensing forecast systems are not currently used (mostly developing countries). Such a project is currently running from South Africa and is called the Severe Weather Forecast Demonstration Project (SWFDP). The goals of this project include: improvement of the lead time of warnings, improved communication between global, regional and National Meteorological Centres (NMC), improved interaction of NMC with disaster management authorities before and during severe weather events (Poolman et al., 2008). One of the gaps identified in the project was that whereas the SWFDP succeeded in improving forecasting systems in the developing countries, there is a serious lack of nowcasting systems, particularly for severe convective storms.

The need to improve very short range and nowcasting services thus applies to the whole southern African region, specifically with regard to convective storm development and evolution. However, there are marked differences between the technologies available to support such services in the various countries of southern Africa. Most southern African countries are heavily reliant on satellite technology due to the limited number of surface and upper-air observations and the limited availability of numerical model output. These countries do not have access to weather radar or lightning information, nor the systems to integrate the data and products from various sources. South Africa, on the other hand, has

Published by Copernicus Publications on behalf of the European Geosciences Union. 


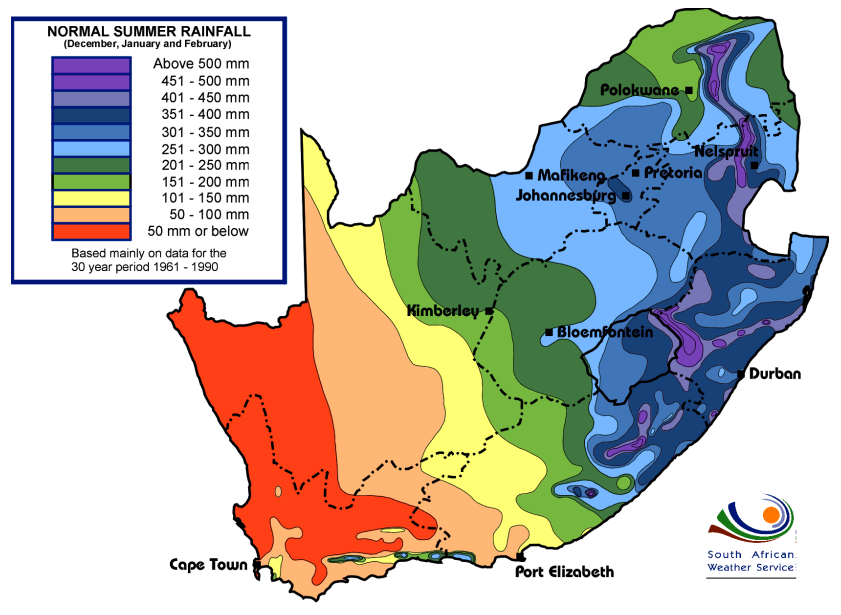

Fig. 1. Normal summer rainfall for South Africa (after Kruger, 2007).

a radar network and a lightning detection network, as well as the means to integrate, display and manipulate these various data sets. Although the approach to be followed for the southern African region outside of South Africa has to be distinctly different from the possibilities for South Africa itself, some of the techniques developed for South Africa might also be useful within the region.

The first aim of the study is to show how the satellite based Quantitative Precipitation Estimation (QPE) provided by the Hydroestimator (HE) can be bias corrected to provide more realistic values over South Africa. Secondly, it will be shown how the HE can be combined in a novel way with the stratiform rainfall field from the local version of the Unified Model, to have a more comprehensive rainfall field. This can be of use in the nowcasting of floods and flash floods.

In this article the enabling technologies for satellite based precipitation estimation will be discussed in Sect. 2. Section 3 provides information on the rainfall patterns and their seasonal variability in South Africa. In Sect. 4 the strengths and weaknesses of the HE will be given, using an example over South Africa. Section 5 will describe the methodology which was used to enhance the satellite based QPE and how this can play a role in the South African Flash Flood Guidance (SAFFG) system. Section 6 describes the first results and a summary and conclusion will be provided in Sect. 7 .

\section{Enabling technology for precipitation measurement in South Africa}

\subsection{Meteosat Second Generation (MSG) satellite data}

Both South Africa and Africa as a whole have had access to the European Geostationary Meteosat Second Generation (MSG) satellite image data and derived products since 2005. The first satellite of the series, then known as MSG,

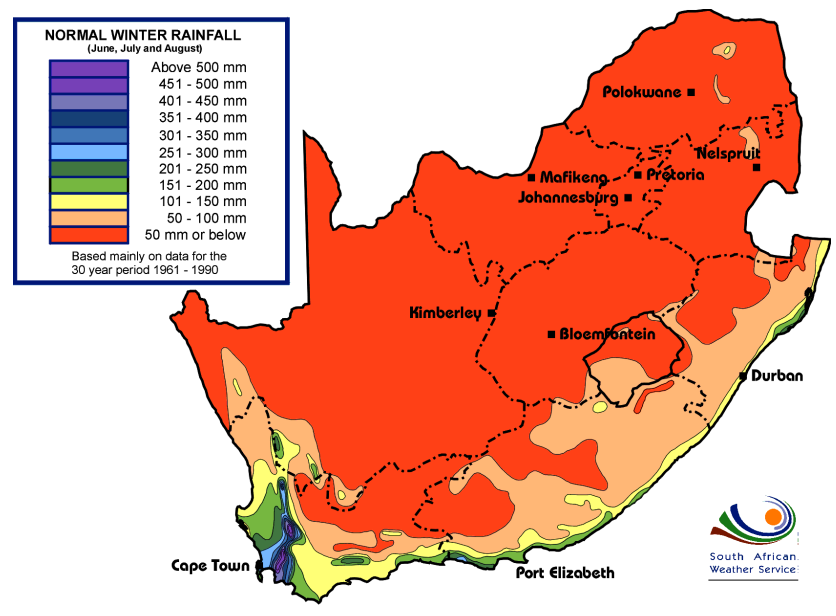

Fig. 2. Normal winter rainfall for South Africa (after Kruger, 2007).

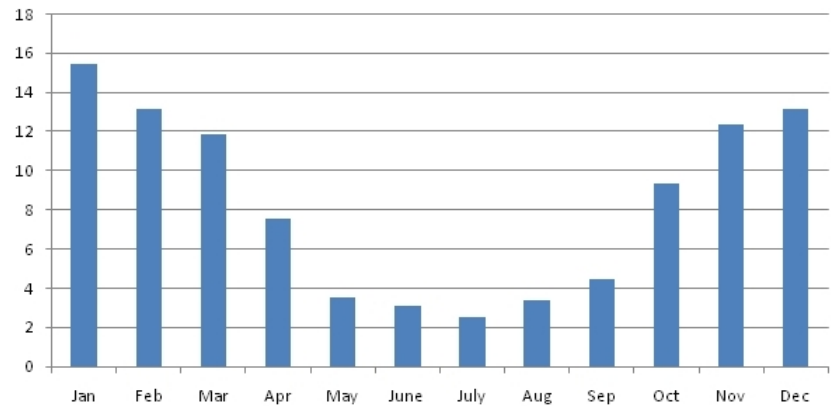

Fig. 3. Percentages of the total rainfall on a monthly basis for 2008 and 2009.

was launched on 28 August 2002 by the European Space Agency on behalf of EUMETSAT (European Organization for the Exploitation of Meteorological Satellites). MSG-2 (Meteosat Second Generation-2) is the follow-on to MSG1 and was launched on 21 December 2005. The two ton, spin stabilized craft carries the same instruments as MSG1 (Spinning Enhanced Visible and InfraRed Imager or SEVIRI and Geostationary Earth Radiation Budget or GERB) and provides the same products. The satellite was renamed Meteosat-9 when it became operational in June 2006 (MSG2 successfully launched, 2005).

This satellite offers a choice of twelve channels to use individually or in combination for various purposes, including nowcasting of convection. For eleven of the twelve channels, image pixels are sampled every $15 \mathrm{~min}$ at intervals of $3 \mathrm{~km}$ over the entire area. The High Resolution Visible (HRV) channel has a sampling distance of just $1 \mathrm{~km}$, with the eastwest scan limited to half of the full earth disc.

\subsection{Radar}

Up until the end of 2009 the South African weather radar network consisted of ten C-band and two S-band radar systems 

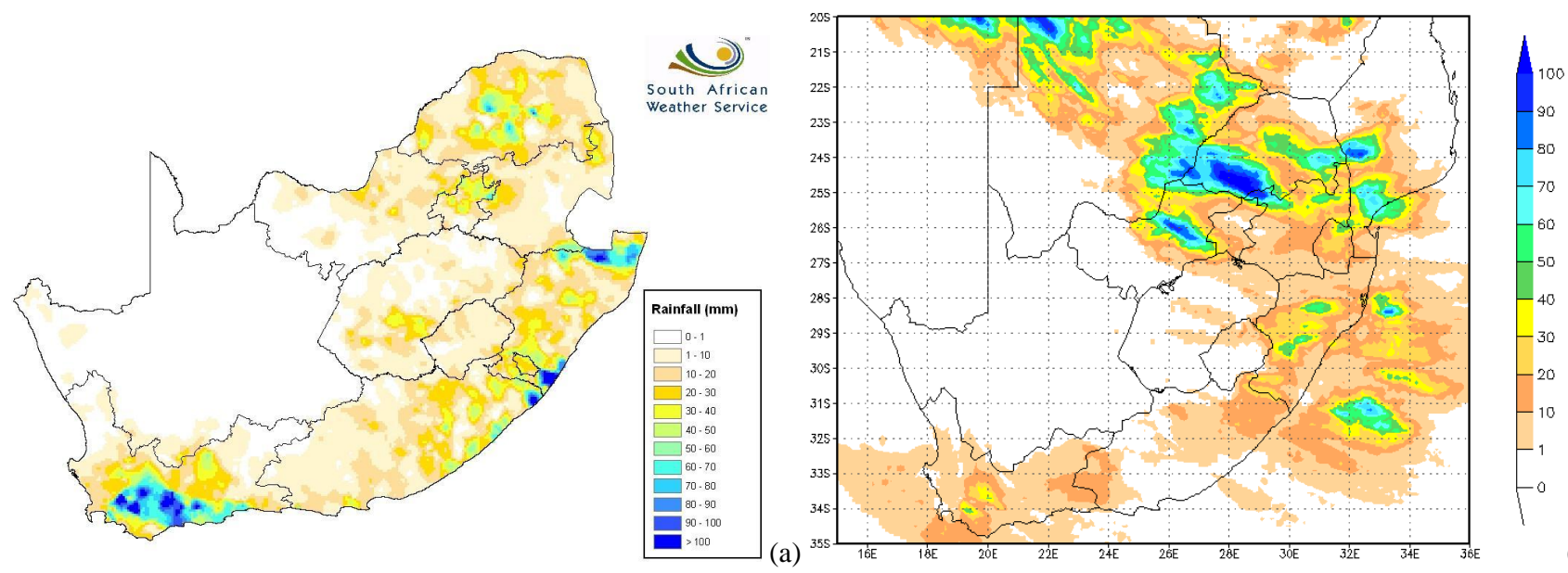

(b)

Fig. 4. Rainfall totals over $24 \mathrm{~h}$ from rain gauges (a) and HE (b) for 12 November 2008.
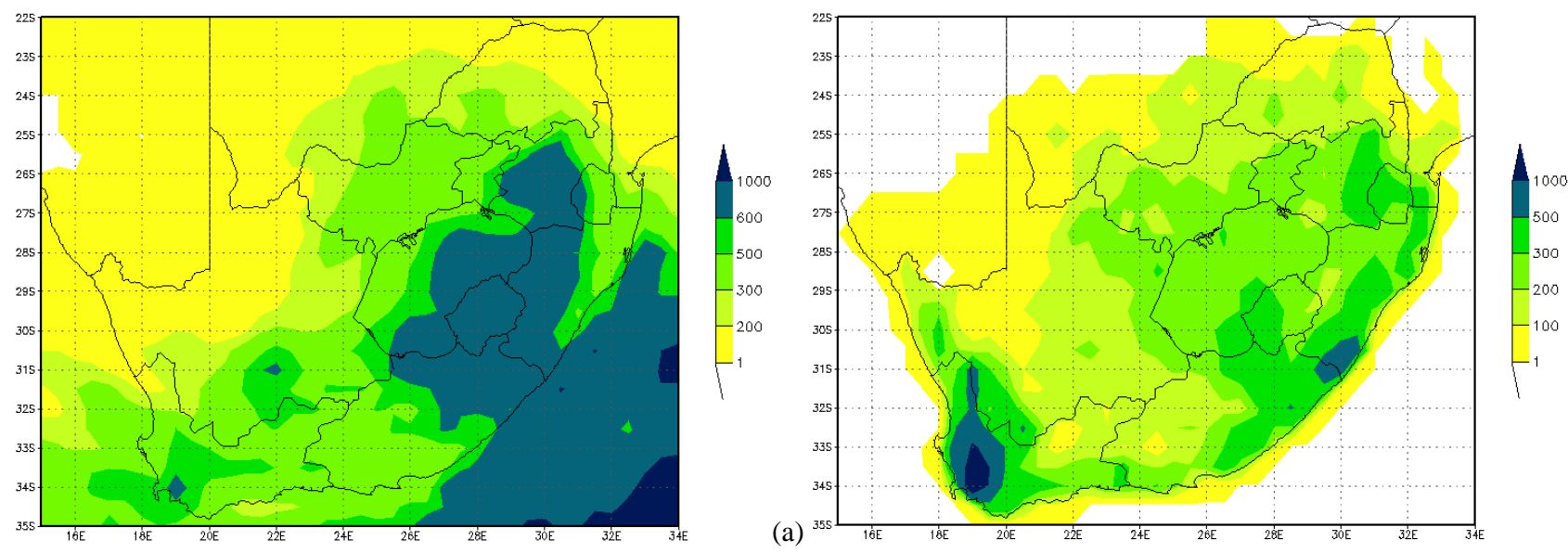

(b)

Fig. 5. HE winter rainfall for 2008 and 2009 (a) and rainfall measured by the gauges in the winters of 2008 and 2009 (b).

that provide coverage over about two-thirds of the country. This network has been used extensively in support of weather predictions, storm identification and aviation applications (De Coning et al., 2010). The spacing of these radars is not ideal for observing stratiform rain because such systems are relatively shallow, resulting in the radar beam overshooting the echo tops at long ranges. Convective storms, however, have relatively deep vertical dimensions allowing them to be observed, at least partially, at longer ranges. Despite the obvious advantages of this system, it still lacked Doppler capabilities and suffered from attenuation. The South African Weather Service (SAWS) is currently in the process of migrating to S-band $(2.8 \mathrm{GHz})$ radar systems. The S-band radar signals undergo far less attenuation than that of the C-band signals. These new radars have sensitive Doppler capabilities with which it is possible to detect the internal wind structure of storms, which will make for better nowcasting of severe storms possible. The enhanced capabilities of the new radar systems will be used for improved radar based precipitation estimates. Although the coverage of the new radar network is improved, complete coverage of South Africa is still not possible, while the rest of southern Africa have very few radar systems available.

\subsection{Unified model}

The Unified Model is the suite of atmospheric and oceanic numerical modelling software, developed and used at the UK Met Office since 1991. The Met Office maintains a suite of versions at particular resolutions that it encourages collaborating partner institutions to use. At the SAWS, the Unified Model runs operationally at a horizontal resolution of $12 \mathrm{~km}$ and is scheduled to run twice daily to provide hourly numerical forecasts of atmospheric conditions for up to $48 \mathrm{~h}$ ahead. The domain of the Unified Model run on South African computers is between $0.48^{\circ} \mathrm{N}$ and $44^{\circ} \mathrm{S}$, and $10^{\circ} \mathrm{W}$ and $56^{\circ} \mathrm{E}$, 

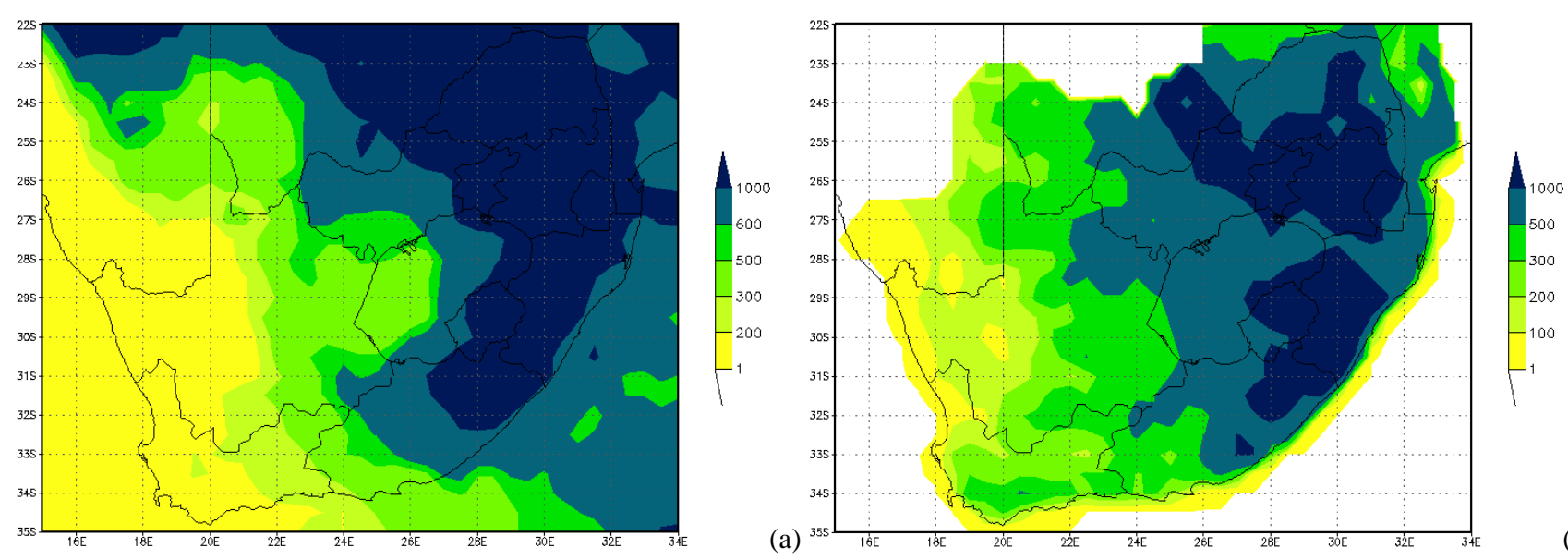

(b)

Fig. 6. HE summer rainfall for 2008 and 2009 (a) and rainfall measured by the gauges in the summer of 2008 and 2009 (b).
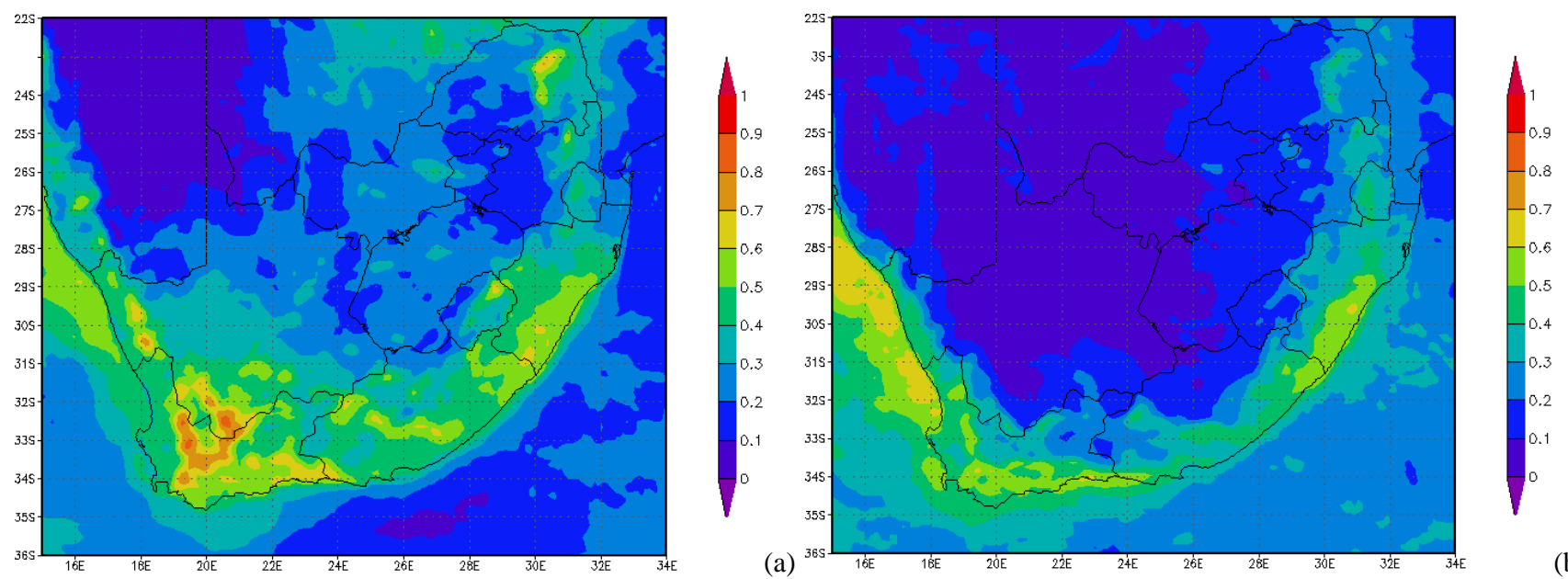

Fig. 7. Ratio of UM stratiform rainfall over UM Total rainfall for winter months (a) and summer months (b) for 2008 and 2009.

with an East/West resolution of $0.11^{\circ}$ and a North/South resolution of $0.1112^{\circ}$.

\subsection{South African rain gauge network}

The SAWS rain gauge network consists of about 1500 rain gauges for $24 \mathrm{~h}$ periods from 06:00 to 06:00 UTC. In 2009 an additional eighty Automatic Rainfall Systems (ARS) have been installed providing rainfall information in real-time. Despite the obvious advantage of being able to measure rainfall in $5 \mathrm{~min}$ intervals, this type of precipitation measurement is still too sparse to provide a comprehensive picture of hourly rainfall over the country.

\subsection{Satellite precipitation estimations - the Hydroestimator}

Area-wide precipitation estimation is one of the most difficult observational challenges of meteorology as a result of the high spatial and temporal variability which is especially pronounced during convective rainfall events. Although rain gauges provide a direct measurement of rainfall, rain gauge networks are far too coarse to capture the smaller scale features of rain fields. Rain gauges are unevenly distributed and, most importantly, they provide point source data and not a representation of a spatial domain (Kondragunta, 2007). Radars can be used to provide an indirect measurement of rainfall, but then the radars need to cover the entire area of interest, be well correlated and have a good radar rainfall relationship. Due to the expensiveness of procuring and maintaining radar systems they are a scare commodity in Africa and thus not a feasible option for this purpose. Although satellite based estimates of rainfall are not as accurate as gauges or radar, its major advantage is the high temporal resolution and spatial coverage, even over oceans, in mountainous regions and sparsely populated areas where rainfall is not measured. Thunderstorms and flash floods often occur in areas between gauges and other surface based networks 

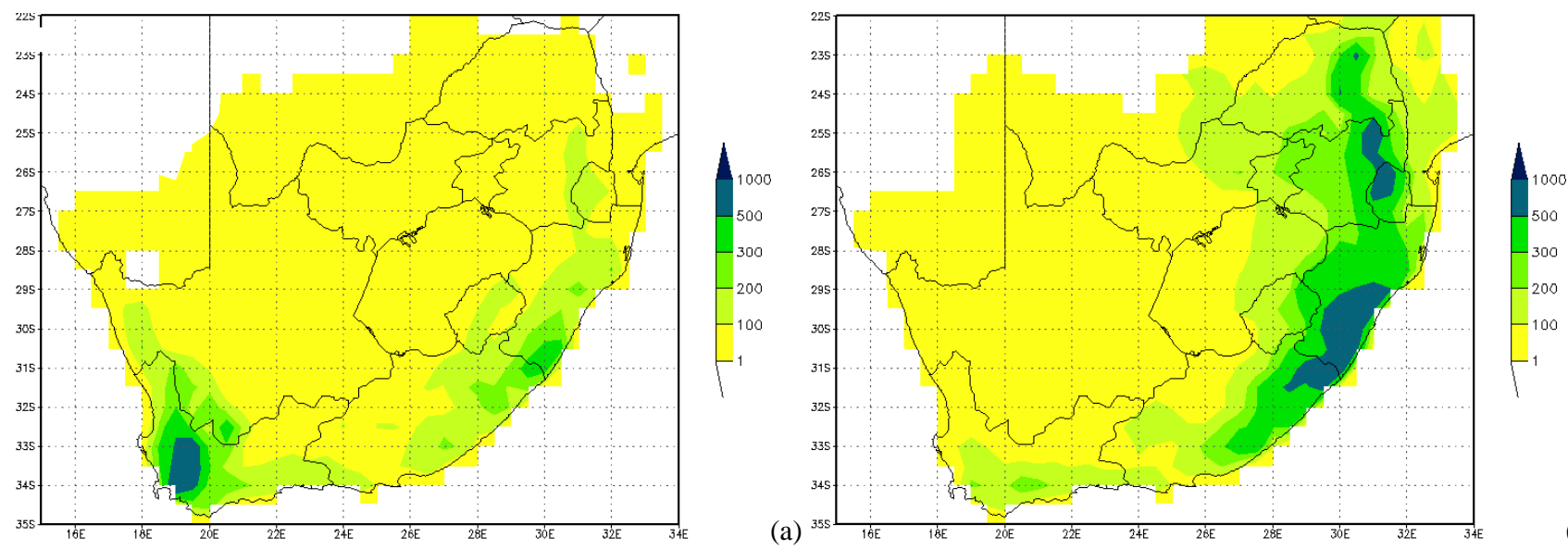

(b)

Fig. 8. Pseudo stratiform rainfall from gauges for winter months (a) and summer months (b) for 2008 and 2009.
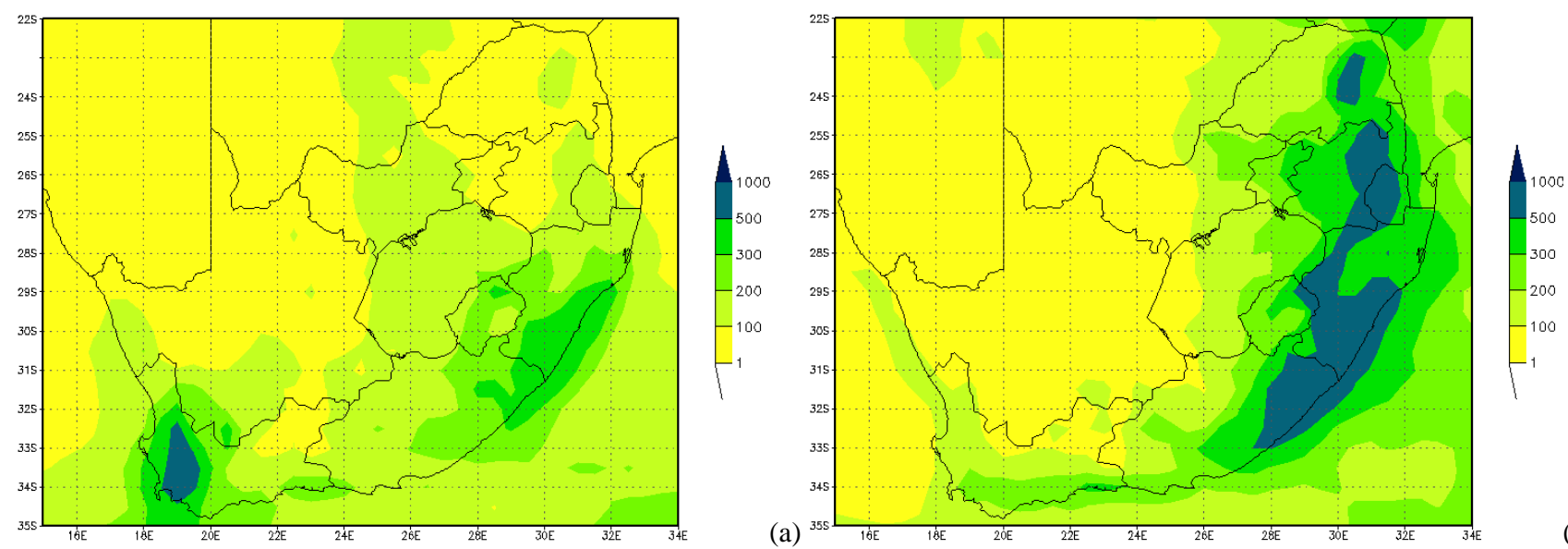

(b)

Fig. 9. UM stratiform rainfall for winter months (a) and summer months (b) for 2008 and 2009.

and thus cannot be detected properly. In such cases satellitederived rainfall can be a "critical tool for identifying hazards from smaller-scale rainfall and flood events." (STAR Satellite Rainfall estimates, 2010).

Satellite precipitation estimates (SPE) offer an excellent way to compensate for some of the limitations of other sources of quantitative precipitation estimations. However, the relationship between satellite-measured radiances and rainfall rates is less robust than that between radar reflectivities and rainfall rates. SPE should thus not be considered as a replacement for radar estimates and gauges but as a complement (Scofield and Kuligowski, 2003).

Scofield (2001) described the status and outlook of operational satellite precipitation algorithms for extreme precipitation events. Since 1978, SPE for flash flood identification has been produced using data from the Geostationary Operational Environmental Satellite (GOES). The National Environmental Satellite, Data and Information Service (NESDIS) developed an automated SPE algorithm for highintensity rainfall called the Autoestimator (AE). The original
AE, developed by Vicente et al. (1998), computes rain rates from $10.7 \mu \mathrm{m}$ brightness temperatures based on a curve that was derived from more than 6000 collocated radar and satellite pixels. The dependence of the initial $\mathrm{AE}$ on radar was a significant problem, because one of the advertised strengths of satellite QPE is its usefulness in regions for which radar and/or rain gauge coverage is unavailable. Another version of the AE, called the Hydroestimator (HE) has been developed which can be used outside of regions of radar coverage without compromising too much accuracy. The HE is mainly dependent on temperature (the higher the cloud, the colder the temperature and the greater the rain rate). More information on the HE and its performance can be obtained from Kuligowski et al. (2005). In general, experience and validation studies (Kuligowski et al., 2001) have shown that SPE tend to overestimate rainfall intensity and spatial coverage of the storm when it is slow moving and has a cold top and SPE tend to underestimate rainfall from warm topped mesoscale convective systems. 

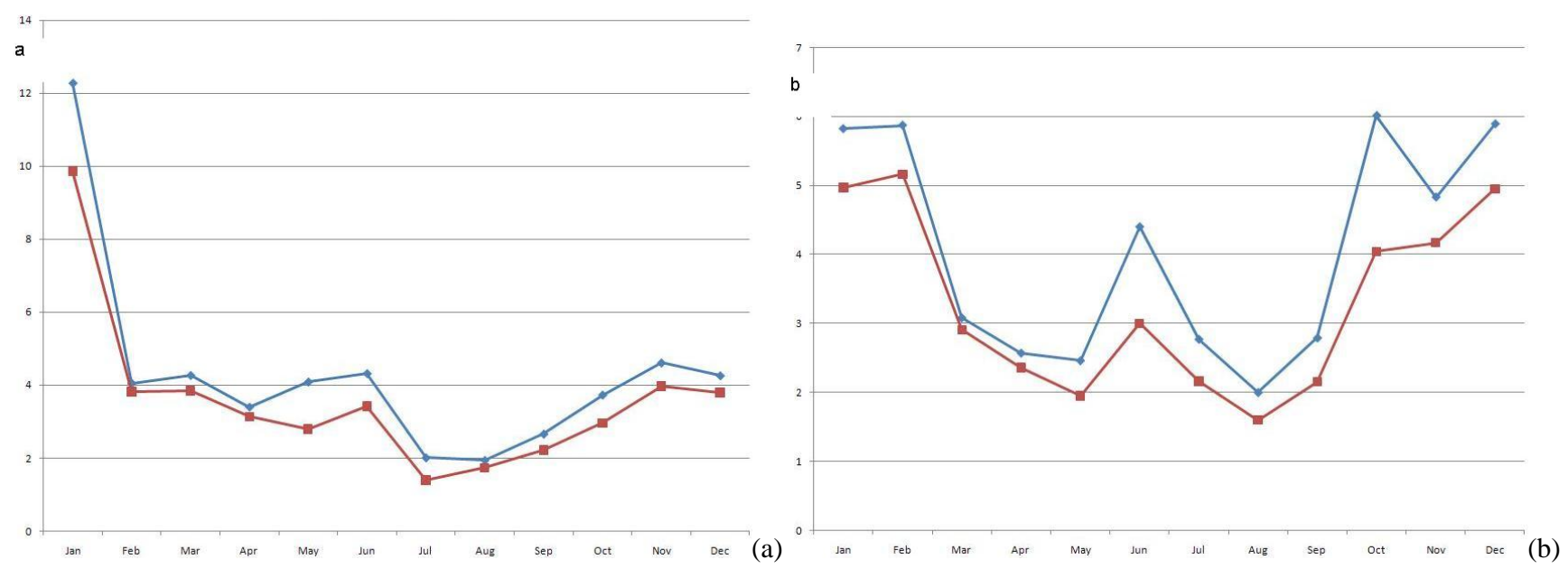

Fig. 10. Mean Absolute Error for 2008 (a) and 2009 (b) on a monthly basis for HE (blue line) and COMB (red line).

Input files for the local HE consist of the IR10.8 channel brightness temperatures of the MSG satellite and model output fields of the SAWS local version of the Unified Model, including: Profiles of the temperature and humidity on 19 levels, from 1000 to $100 \mathrm{hPa}$, every $50 \mathrm{hPa}$, surface pressure and $700 \mathrm{hPa}$ wind field. Before the actual HE code is run, parallax and zenith angle corrections are made. The parallax correction helps to position the rainfall cores more accurately, which plays an important role in smaller scale storms (Vicente et al., 2002). The HE is available in the same domain as the local version of the Unified model (i.e. between $0.48^{\circ} \mathrm{N}$ and $44^{\circ} \mathrm{S}$ and between $10^{\circ} \mathrm{W}$ and $56^{\circ} \mathrm{E}$ ).

Despite the simplicity of this precipitation estimation algorithm, it is still used in many countries around the world. There are, of course, more accurate and also more involved precipitation algorithms available, but the requirements for these algorithms are currently beyond the capabilities in South and southern Africa. In southern Africa a precipitation estimator, independent of radars is required to provide data in real time and thus the HE suits the need.

The International Precipitation Working Group (IPWG) is one of the working groups of the Coordination Group for Meteorological Satellites (CGMS). The work done in this group concentrates on "operational and research satellite based quantitative precipitation measurement issues and challenges" (http://www.isac.cnr.it/ ipwg). Statistical evaluation performed on the HE in the United States show that the $\mathrm{HE}$ is performing very well; with a correlation between the $\mathrm{HE}$ and the rain gauges on an hourly basis of more than 0.7 in some examples.

\subsection{Accumulation products for the $\mathrm{HE}$}

An important part of the warning process for flooding and/or flash flooding is knowledge of the amount of rain which fell in previous time periods, from one hour to several hours. In regions where rain gauges are sparse a satellite based accumulation of precipitation can go a long way to help a forecaster to know that a significant amount of rain has fallen recently. Accumulation products of the $\mathrm{HE}$ have been developed for $1 \mathrm{~h}, 3 \mathrm{~h}, 6 \mathrm{~h}, 24 \mathrm{~h}, 10$ days and 1 month. These products are updated operationally on a rolling time average basis on the Regional Specialized Meteorological Centre (RSMC) webpage (http://old.weathersa.co. $\mathrm{za} /$ RSMCLoginServlet). This website was developed to aid National Meteorological Centres (NMC) of southern African countries with guidance products in the SWFDP project, model output as well as warnings for possible floods, strong wind are provided.

\subsection{The South African Flash Flood Guidance system (SAFFG)}

Flooding events in recent years in South Africa, and particularly in the southwestern and southeastern coastal regions, dramatically demonstrated the devastating impact of flash floods on the country. In response to this the SAWS and the National Disaster Management Centre (NDMC) embarked on a collaborative project for the development and implementation of a flash flood warning system in flash flood prone regions, called the South African Flash Flood Guidance (Poolman, 2010). The development of the SAFFG system was in a testing phase during the first half of 2010 and became operational in October 2010.

The SAFFG system is a hydro-meteorological modelling system combining real-time meteorological information, such as quantitative rainfall estimation from weather radar, satellite and rain gauges, with hydrological modelling of the soil moisture conditions and resultant flash flood potential in 1633 small river basins (on average $50 \mathrm{~km}^{2}$ ) in five flash flood prone regions over South Africa. One of the flash flood prone areas is located along the southern coastal regions 

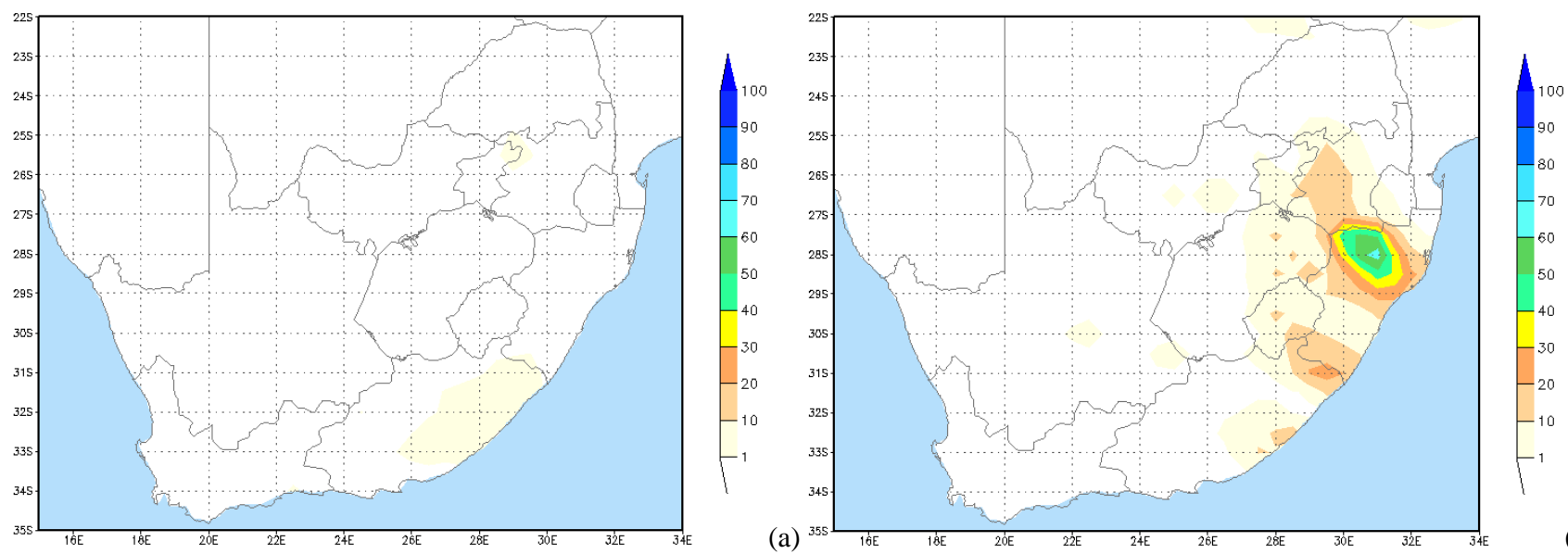

(b)
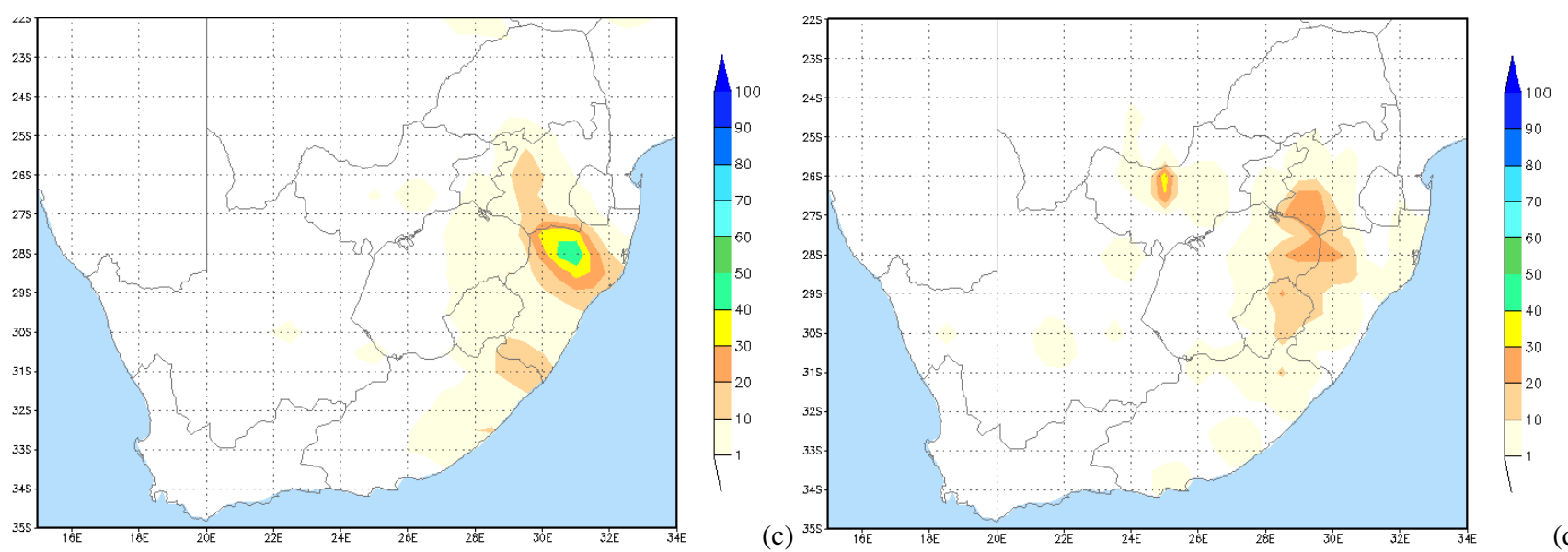

(d)

Fig. 11. UMS precipitation total for $24 \mathrm{~h}$ (a), HE precipitation total for $24 \mathrm{~h}$ (b), COMB precipitation total for $24 \mathrm{~h}$ (c) and the total rainfall as measured by the rain gauges (d) for 28 January 2008.

where radar coverage is not available. In this region the SAFFG system is configured for $200 \mathrm{~km}^{2}$ catchments and dependant only on the satellite rainfall estimates and gauges data.

The SAFFG uses the quantitative rainfall estimates of the previous 24 hours from radar, satellite and rain gauges to pre-calculate every hour the necessary hydrological information of each relevant small river basin (soil moisture, subsequent run-off) to determine the amount of rain needed over the basin that will lead to bank full at the outlet of the river, i.e. start of flooding. When this value is compared in real time to the amount of rain falling over each basin (as estimated from real-time monitoring rain gauges, radar and satellite) river basins in danger of flash flooding can be quickly identified. The SAFFG depends heavily on the quality of QPE products from radar and satellite as input to the hydrologic models. It is therefore very important to improve the rainfall estimation from radar and satellite information as a primary input into the hydrological modelling.

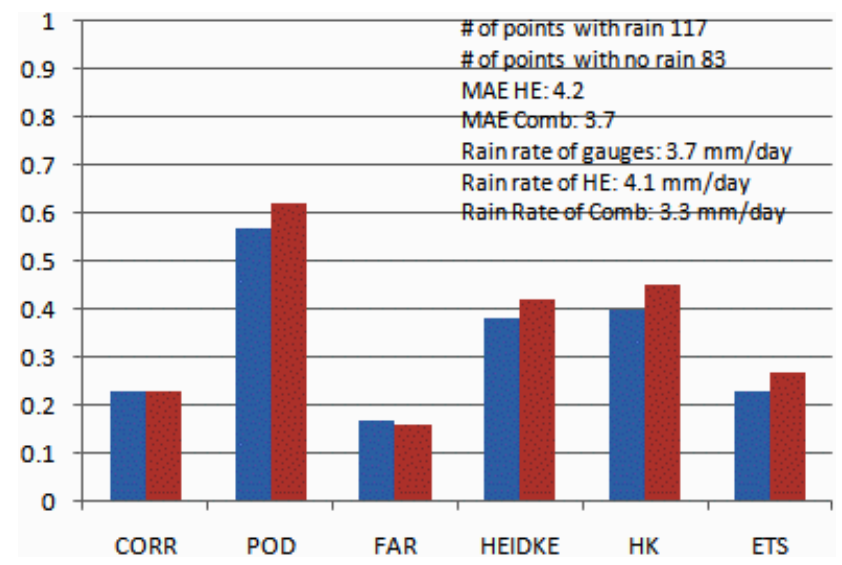

Fig. 12. Statistical evaluation of 28 January 2008 for HE (blue) and COMB (red). 

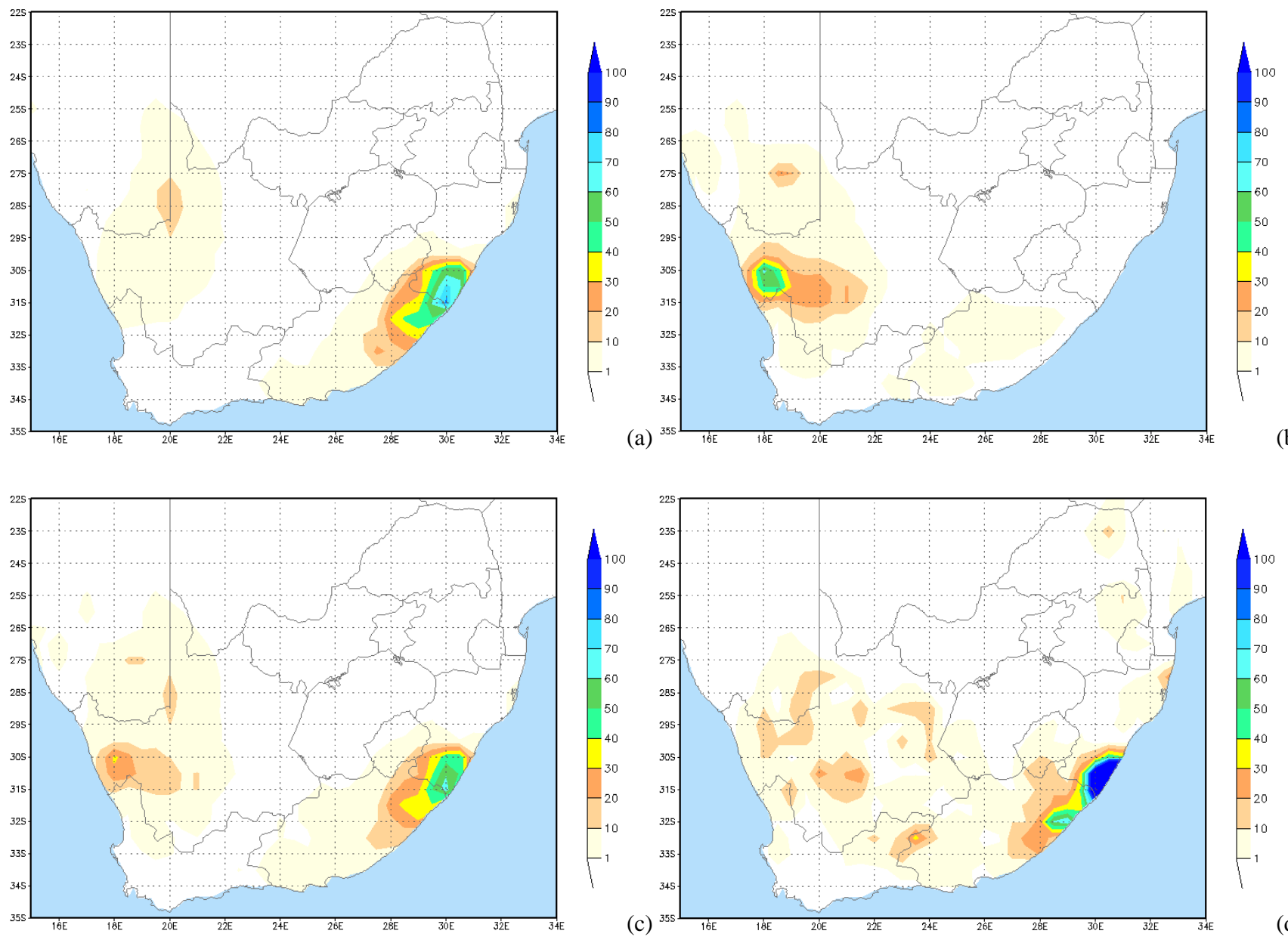

(b)

Fig. 13. Unified Model stratiform precipitation total for $24 \mathrm{~h}$ (a), Hydroestimator precipitation total for $24 \mathrm{~h}$ (b), the combined product from $\mathrm{HE}$ and $\mathrm{UM}$ for $24 \mathrm{~h}$ (c) and the total rainfall as measured by the rain gauges (d) for 17 June 2008.

The WMO is developing a similar flash flood guidance system (called the SADC SARFFG) aiming for implementation over seven southern African countries in 2011. The SADC SARFFG system will cover the rest of South Africa and six other countries where there are no radar coverage at the coarser $200 \mathrm{~km}^{2}$ resolution. This system will therefore depend primarily on satellite QPE as precipitation input for modelling soil moisture and flash flood guidance over large parts of southern Africa. A thorough evaluation of the newly implemented SAFFG system will be done in due course. Such an evaluation falls outside the scope of this paper.

\section{South Africa climate and rainfall patterns}

Kruger (2007) did a thorough analysis of the rainfall patterns of South Africa. The highest rainfall occurs along the eastern escarpment, in particular, along the mountain ranges in the southeast. Rainfall generally decreases from east to west; the highest amounts in the east have an average of $800 \mathrm{~mm}$ per year, while amounts of less than $200 \mathrm{~mm}$ per year occur in the west. Although there is a distinct relationship between rainfall and elevation, other factors such as whether the rainfall is convective or stratiform in nature, also plays a role. Summer rainfall occurs mainly over the northern interior of the country (Fig. 1), mostly in the form of convective thunderstorms. A tropical influence is felt when moisture from the tropics enters the country in January to March and tropical rain showers are common with less heat generated convection. In the winter months the southwestern parts and coastal regions receive its rainfall mainly as a result of cold fronts and high pressure systems ridging along the coast (Fig. 2). The influence of orography contributes to the higher rainfall over the eastern escarpment when combined with the inflow of moist air from the Indian Ocean (Kruger, 2007). The percentage of the total rainfall on a monthly basis for 2008 and 2009 is shown in Fig. 3; it is evident that the summer months contribute most of the country's annual rainfall. 

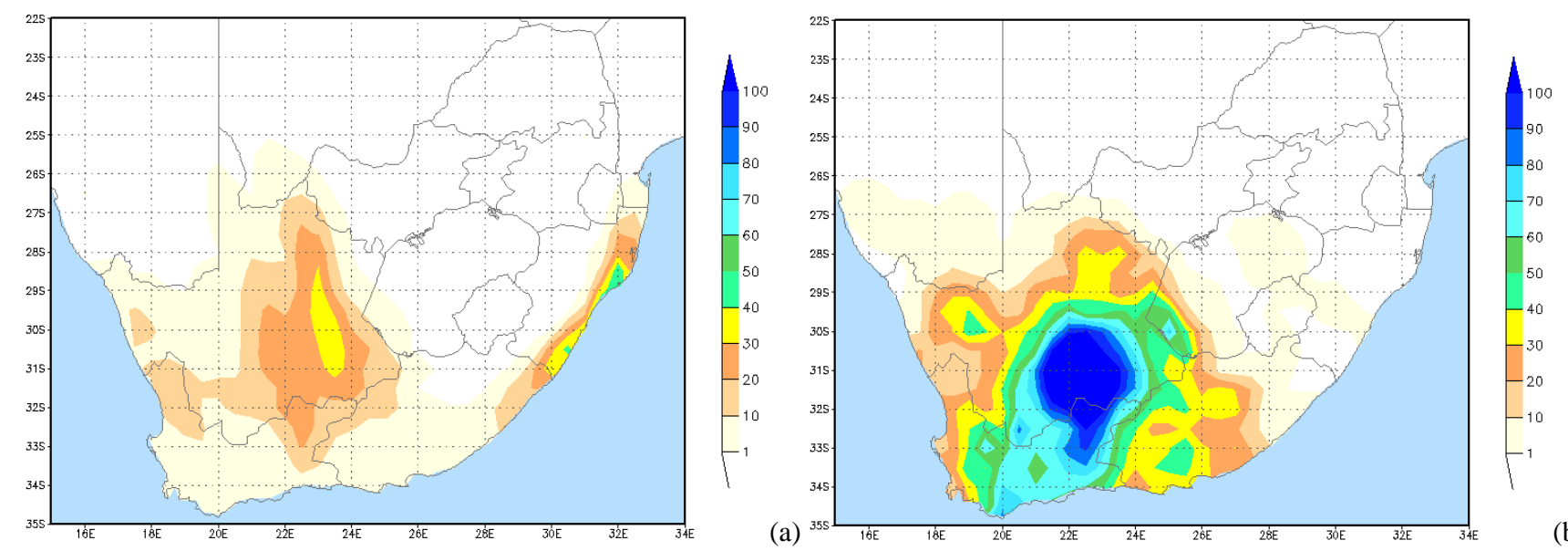

(b)
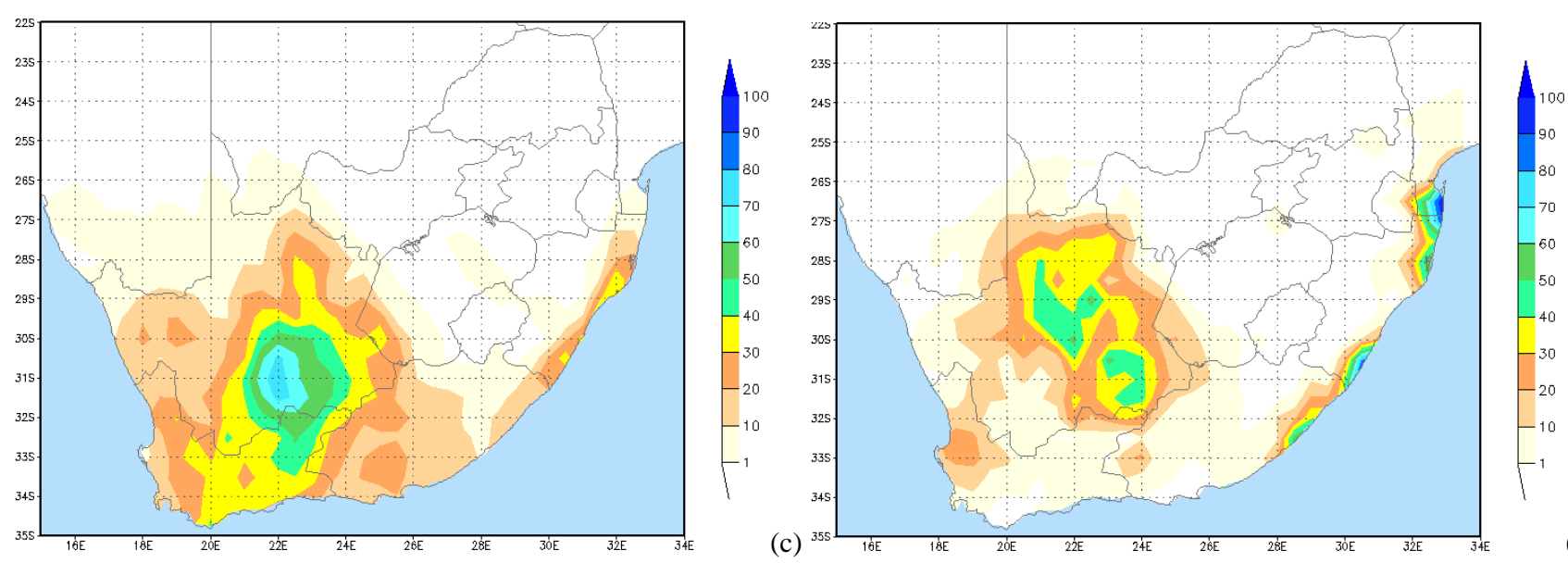

(d)

Fig. 14. Unified Model stratiform precipitation total for $24 \mathrm{~h}$ (a), Hydroestimator precipitation total for $24 \mathrm{~h}$ (b), the combined product from $\mathrm{HE}$ and $\mathrm{UM}$ for $24 \mathrm{~h} \mathrm{(c)} \mathrm{and} \mathrm{the} \mathrm{total} \mathrm{rainfall} \mathrm{as} \mathrm{measured} \mathrm{by} \mathrm{the} \mathrm{rain} \mathrm{gauges} \mathrm{(d)} \mathrm{for} 18$ June 2008.

\section{Strengths and weaknesses of the HE}

An example (Fig. 4 ) is shown comparing the $24 \mathrm{~h}$ rain gauge totals to the $24 \mathrm{~h}$ totals from the HE on 12 November 2008. Only rain gauges from South Africa are available and therefore the domain for comparison is confined to the areas within the borders of South Africa. The rain gauge totals (Fig. 4a) show widespread rain, except in the western interior. The highest totals were recorded in the southwestern parts as well as on the southeastern coast. Spatially, the HE looks similar (Fig. 4b), but the rainfall over the central interior was not detected by the HE. The HE put the highest emphasis in the northern interior, with rainfall totals close to $100 \mathrm{~mm}$ which is too high in comparison with the gauges. The rainfall along the coasts was detected by the HE, but the amount of rain was underestimated by the HE.

This example confirms that the HE differs substantially in intensity from the measurements by the rain gauges when using a $24 \mathrm{~h}$ accumulation. The aerial extent of where precipitation occurs is reasonable. The HE performs best for convective events, but overestimates the convection intensity. As expected, rainfall from stratiform weather systems along the coasts is underestimated by this algorithm.

\section{Methodology}

The first step to improve on the hourly satellite based QPE is to determine the bias of the HE. The other disadvantage of the HE (underestimation of stratiform rain events) will be addressed by combining the HE with rainfall fields from the Unified Model in a new field. Experience has shown that the Unified Model usually handles synoptic scale weather features such as frontal systems well. These systems are accompanied by stratiform rainfall. Stratiform rainfall usually affects the coastal areas of South Africa and is predicted more accurately than the convective precipitation accompanying thunderstorms. The stratiform precipitation field from the Unified Model will be compared to gauge measurements in a novel way allowing this field to also be bias-corrected. 


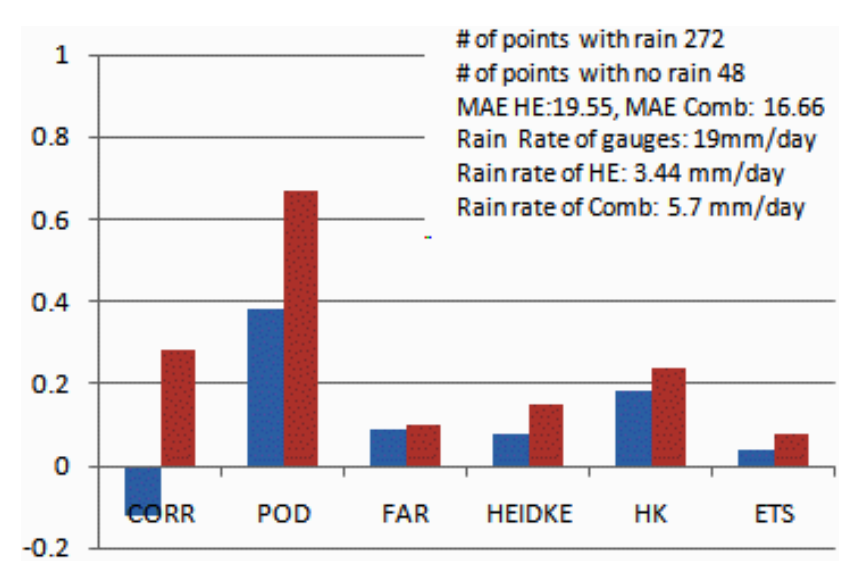

Fig. 15. Statistical evaluation of 17 June 2008 for HE (blue) and COMB (red).

Subsequently the bias corrected stratiform rainfall field will be used in combination with the bias corrected HE field to supply a more comprehensive precipitation estimation to include not only the convective events, but also the stratiform events more accurately.

\subsection{Bias correction of the $\mathrm{HE}$}

Data from the HE are available since January 2008. The HE from January 2008 until December 2009 was used to determine the average area ratio between the HE and the rain gauges in $0.5 \times 0.5^{\circ}$ grid boxes. Due to the fact that this is a very short "climate" to base findings on, it was decided to divide the data into six month periods instead of individual months for all bias correction calculations. It was clear that the months from November to April and May to October, respectively, had similar ratios and thus November to April will be termed the "summer" months and May to October will be termed the "winter" months.

In Fig. 5 the two year rainfall total over the country for the winter months are shown in panel a and the two year rain gauge total in panel b. Figure 6 is similar for the summer months. The area average of the ratio for the summer months (November to April) is 1.3 and the area average for the winter months (May to October) is 2.1. The HE is thus overestimating by a factor 1.3 in summer and a factor of 2.1 in winter. Using these two years' data it seems that if $75 \%(\sim 1 / 1.3)$ of the HE is used in summer months and $50 \%(\sim 1 / 2.1)$ in winter months, the HE totals and rain gauge totals might be more aligned.

\subsection{Bias correction of the stratiform rainfall field from the UM}

The bias correction of the stratiform rainfall field provided by the Unified Model can be done using the rain rate of the automatic rain gauges and attempting to identify those periods in which the rain rate approximates that expected from

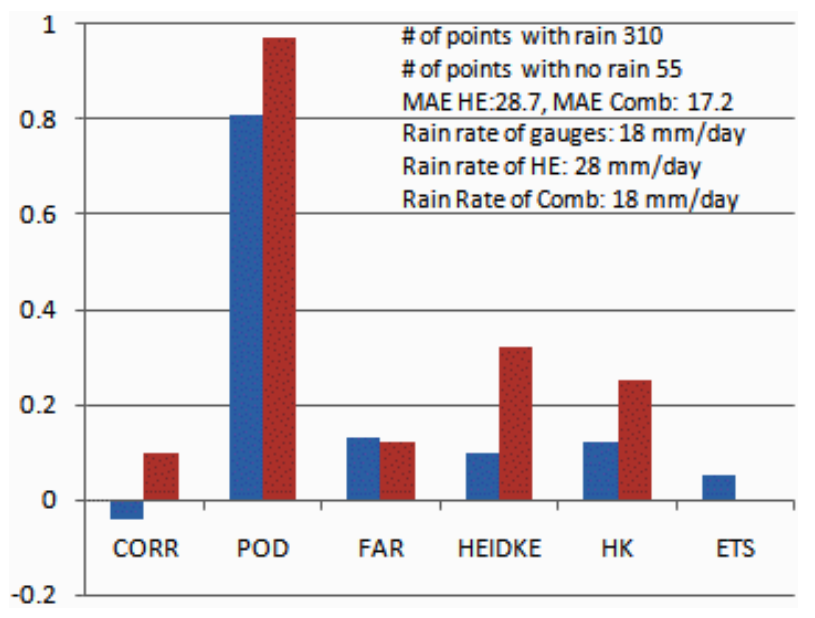

Fig. 16. Statistical evaluation of 18 June 2008 for HE (blue) and COMB (red).

stratiform rainfall. Unfortunately, there are not enough of these gauges operational over the country yet.

An alternative solution is to use the ratio of the UM stratiform field to the UM total rainfall field to estimate the percentage of the observed rainfall that can be attributed to stratiform rainfall. Figure 7 show this ratio for the months from May to October and November to April. This was calculated using the hourly UM derived rainfall fields from January 2008 to December 2009. It is evident that the frontal systems contribute more to stratiform rainfall during the winter months in the southwestern parts of the country. During the summer months stratiform rainfall also occur along the eastern and northeastern escarpment of the country. If these winter and summer ratios are applied to the rain gauge totals for the winters and summers of the same two year period, a pseudo stratiform observation can be calculated for winter (Fig. 8a) and summer (Fig. 8b). In Fig. 9 the UM stratiform fields for winter (panel a) and summer (panel b) are shown. Comparing Figs. 8 and 9 it is evident that the precipitation field provided by the model also over estimates the rainfall measured by gauges, but less so than the HE. Calculating the ratio of the UM stratiform field over this pseudo stratiform observation in areas where more than $150 \mathrm{~mm}$ were recorded in this two years period (i.e. in regions where stratiform rainfall makes a significant contribution), provides a bias-correction for the UM stratiform field of $1.25(\sim 80 \%)$ for winter months and $1.4(\sim 70 \%)$ for summer months.

\subsection{Combining the bias corrected HE and UM stratiform fields into a new precipitation field}

The maximum value of either the bias-corrected HE (as mentioned in Sect. 5.1) or the bias-corrected UM stratiform rainfall field (as mentioned in Sect. 5.2) is used to compute a new rainfall field for each grid box. The maximum of the two values are used to ensure that the extreme values captured 

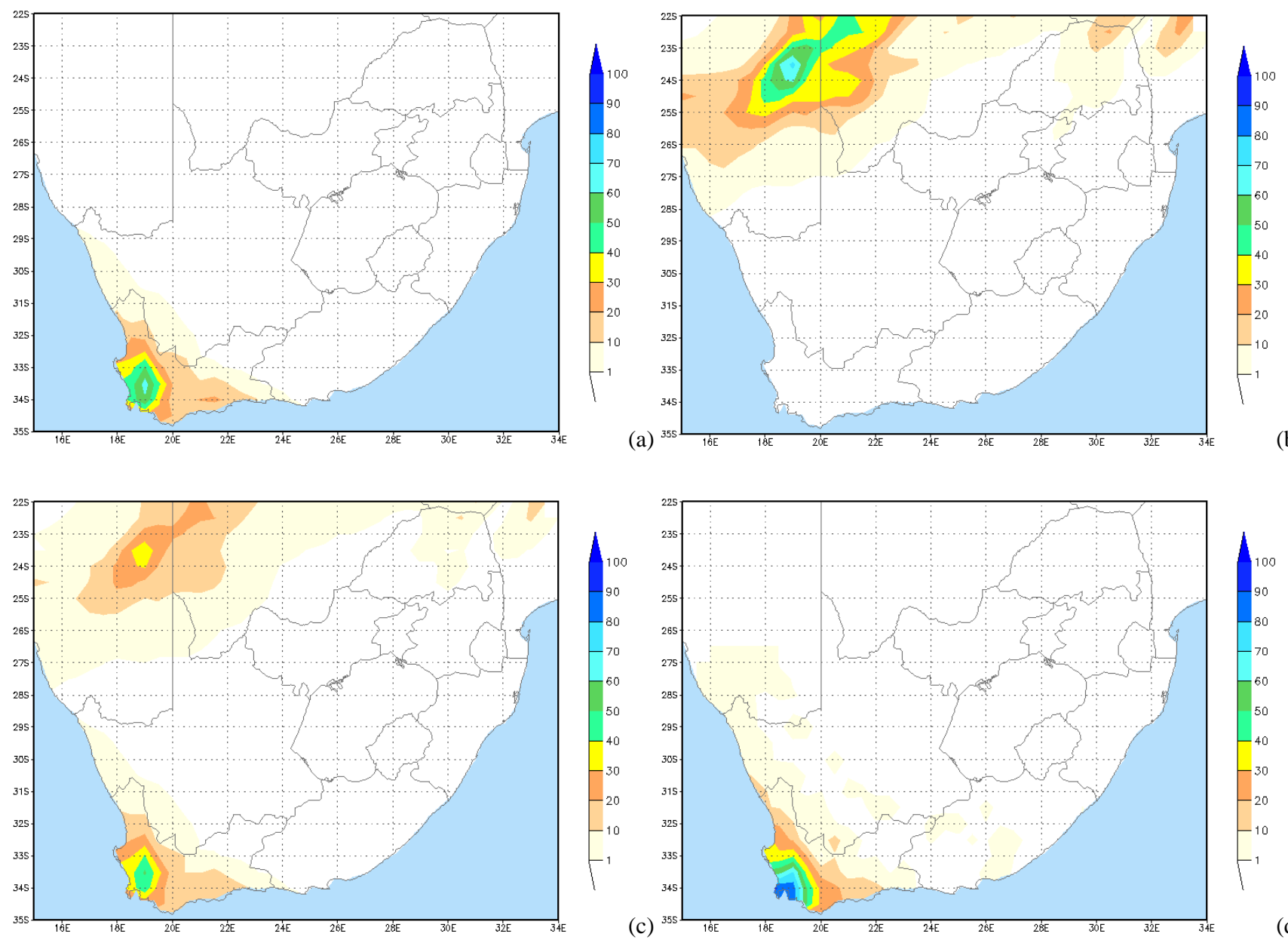

(d)

Fig. 17. Unified Model stratiform precipitation total for $24 \mathrm{~h}$ (a), Hydroestimator precipitation total for $24 \mathrm{~h}$ (b), the combined product from $\mathrm{HE}$ and UM for $24 \mathrm{~h}$ (c) and the total rainfall as measured by the rain gauges (d) for 12 July 2009.

by either rainfall mechanism are not missed in areas where both rainfall types occur during a given period. It should be remembered that the HE is primarily designed for cold cloud top convective rainfall although it sometimes captures a small fraction of the stratiform rainfall that are associated with cold cloud tops. This combined product represents a rainfall field which reflects both bias corrected convective as well as bias corrected stratiform rainfall. This calculation can be done every 15 minutes (when a new HE field becomes available) and it can be accumulated into hourly files, to make it useful for flood and/or flash flood forecasting. This product will be referred to as COMB in the rest of the text.

This procedure was followed for all the days of 2008 , to create hourly fields. The IPWG uses $0.25 \times 0.25^{\circ}$ grid boxes for evaluation purposes and also evaluates on an hourly basis. Due to the relative shortage of rain gauges in South Africa compared to the USA, it was decided to accumulate the hourly fields into $24 \mathrm{~h}$ totals for each day using $0.5 \times 0.5^{\circ}$ grid boxes. Daily rainfall totals of the HE and the COMB could then be compared to the daily rainfall totals from the

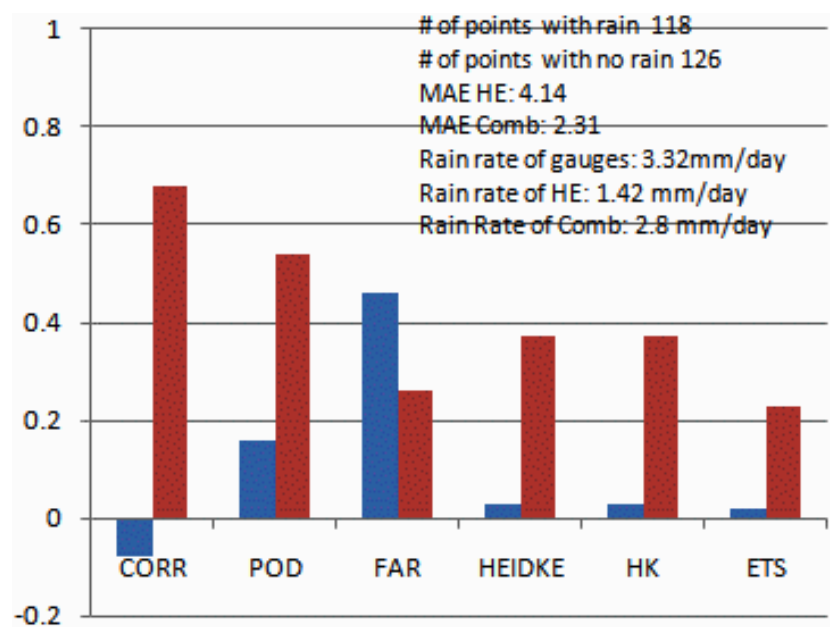

Fig. 18. Statistical evaluation of 12 July 2009 for HE (blue) and COMB (red). 
rain gauges. The $24 \mathrm{~h}$ totals were calculated from 06:00 UTC to 06:00 UTC each day. Rain gauges are only available inside the borders of South Africa. A mask was thus created to outline the country to ensure that only values of $\mathrm{HE}$ or the combined precipitation product were taken into account where it could be evaluated against rain gauge measurements.

Similar to the approach followed by the IPWG (http:// www.isac.cnr.it/ ipwg/) the daily rainfall fields were evaluated using the contingency table approach, calculating the traditional scores such as probability of detection, false alarm ratio, Hanssen-Kuipers score (also known as True Skill Statistic, or Pierces' skill score), Equitable threat score and Heidke Skill Score (Wilks, 2005). The correlation coefficient, mean absolute error and number of points with and without rain were also calculated. All the statistical calculations were done with rainfall of less than $1 \mathrm{~mm}$ implying no rain and anything more than $1 \mathrm{~mm}$ implying rainfall.

\section{Results}

The expectation is that the COMB should be slightly better in summer months, due to the bias correction applied to the HE. The COMB should be a bigger improvement on the HE in the winter months where the stratiform events will be captured better.

\subsection{Monthly values}

The amount of data points with rain and with no rain for each month of 2008 and 2009 are listed in Table 1. In the last column a Rain/No Rain ratio is given. This ratio confirms that seasonal rainfall patterns discussed before.

In Tables 2 and 3, respectively, the average monthly statistics for 2008 and 2009 are given comparing the HE and the Combination rainfall product.

\subsubsection{Correlation coefficient}

Looking at the second and third columns of Tables 2 and 3, is it clear that the correlation coefficient of the COMB was better than the HE in all months. In summer months there are more grid boxes with rainfall and the statistical significance of the correlation coefficients are better than in the winter months. Relative to the HE the COMB is notably better in the winter months, when the HE alone missed the stratiform events which was only evident in combination with the stratiform rainfall field from the UM.

\subsubsection{Probability of detection}

If the average of the entire year is used, there is a $10 \%$ increase of the POD in both years using the COMB. As expected the POD of the HE is worse during the winter months, while the COMB is adding the most value by incorporating the stratiform rainfall field. The POD of HE is best (around
Table 1. Number of grid boxes with and without rainfall for 2008 and 2009.

\begin{tabular}{|c|c|c|c|c|c|c|}
\hline & \multicolumn{2}{|c|}{$\begin{array}{c}\text { Average number of } \\
\text { points with rain }\end{array}$} & \multicolumn{2}{|c|}{$\begin{array}{l}\text { Average number of } \\
\text { points without rain }\end{array}$} & \multicolumn{2}{|c|}{$\begin{array}{l}\text { Rain points/ } \\
\text { No rain ratio }\end{array}$} \\
\hline & 2008 & 2009 & 2008 & 2009 & 2008 & 2009 \\
\hline Jan & 161 & 153 & 70 & 71 & 2.3 & 2.2 \\
\hline Feb & 159 & 2.8 & 85 & 84 & 1.9 & 2.5 \\
\hline Mar & 153 & 101 & 84 & 70 & 1.8 & 1.4 \\
\hline Apr & 84 & 83 & 67 & 74 & 1.3 & 1.1 \\
\hline May & 74 & 55 & 63 & 53 & 1.2 & 1.0 \\
\hline Jun & 72 & 97 & 54 & 75 & 1.3 & 0.9 \\
\hline Jul & 25 & 43 & 31 & 42 & 0.8 & 1.0 \\
\hline Aug & 38 & 42 & 44 & 41 & 0.9 & 1.0 \\
\hline Sep & 38 & 57 & 39 & 47 & 0.9 & 1.2 \\
\hline Oct & 88 & 141 & 68 & 73 & 1.3 & 1.9 \\
\hline Nov & 135 & 108 & 73 & 64 & 1.8 & 1.7 \\
\hline Dec & 103 & 109 & 62 & 56 & 1.7 & 1.9 \\
\hline
\end{tabular}

$38 \%$ ) during the summer months, while the COMB exceeds $40 \%$ in more than one summer month.

\subsubsection{False alarm ratio}

In some months the FAR of the COMB is slightly higher (worse) than the FAR of the HE, but on average for 2008 and 2009 , the FAR of COMB $(\sim 31 \%)$ is still less than the FAR of the HE $(\sim 34 \%)$.

\subsubsection{Hanssen Kuiper score and Heidke skill score}

For all of these scores the COMB is better than HE for the individual months as well as on average for all 12 months $( \pm 5 \%)$.

\subsubsection{Mean absolute error}

The MAE of the COMB is smaller than the MAE of the HE in all months of 2008 and 2009, respectively (Fig. 10a and b). This is contributed to the BIAS correction applied to the HE before combining it with the stratiform fields. This is specifically evident in January 2008.

\subsection{Daily values}

Some case days were used to demonstrate the specific weather situations as well as the effect of the HE, UM stratiform field and the COMB. All of these products are $24 \mathrm{~h}$ rainfall totals on a $0.5^{\circ} \times 0.5^{\circ}$ resolution.

\subsubsection{Example 1: 28 January 2008}

In the summer case (Fig. 11) it is clear that stratiform precipitation (top left) didn't play a significant role. The HE (top right) captured the convective rainfall and after the bias correction was applied (bottom left), it is closer to rainfall 
Table 2. Statistical evaluation of HE and COMB in 2008.

\begin{tabular}{|c|c|c|c|c|c|c|c|c|c|c|c|c|}
\hline & \multicolumn{2}{|c|}{$\begin{array}{l}\text { Correlation } \\
\text { Coefficient }\end{array}$} & \multicolumn{2}{|c|}{ POD } & \multicolumn{2}{|c|}{ FAR } & \multicolumn{2}{|c|}{$\begin{array}{c}\text { Heidke Skill } \\
\text { Score }\end{array}$} & \multicolumn{2}{|c|}{$\begin{array}{c}\text { Hanssen Kuiper } \\
\text { Discriminant }\end{array}$} & \multicolumn{2}{|c|}{$\begin{array}{c}\text { Mean Abs } \\
\text { Error }\end{array}$} \\
\hline & $\mathrm{HE}$ & Comb & $\mathrm{HE}$ & Comb & $\mathrm{HE}$ & Comb & $\mathrm{HE}$ & Comb & $\mathrm{HE}$ & Comb & $\mathrm{HE}$ & Comb \\
\hline Jan & 0.22 & 0.23 & 0.34 & 0.41 & 0.17 & 0.19 & 0.14 & 0.19 & 0.18 & 0.21 & 12.28 & 9.87 \\
\hline Feb & 0.22 & 0.22 & 0.26 & 0.29 & 0.14 & 0.21 & 0.15 & 0.15 & 0.19 & 0.19 & 4.05 & 3.82 \\
\hline Mar & 0.22 & 0.25 & 0.3 & 0.36 & 0.21 & 0.2 & 0.15 & 0.17 & 0.19 & 0.21 & 4.27 & 3.85 \\
\hline Apr & 0.09 & 0.09 & 0.22 & 0.23 & 0.4 & 0.45 & 0.1 & 0.1 & 0.12 & 0.12 & 3.4 & 3.14 \\
\hline May & 0.08 & 0.21 & 0.19 & 0.28 & 0.41 & 0.36 & 0.05 & 0.11 & 0.06 & 0.12 & 4.09 & 2.8 \\
\hline Jun & 0.04 & 0.14 & 0.18 & 0.27 & 0.33 & 0.25 & 0.08 & 0.15 & 0.08 & 0.15 & 4.32 & 3.42 \\
\hline Jul & -0.02 & 0.24 & 0.04 & 0.21 & 0.69 & 0.37 & -0.03 & 0.08 & -0.03 & 0.08 & 2.01 & 1.4 \\
\hline Aug & -0.01 & 0.05 & 0.01 & 0.14 & 0.54 & 0.45 & 0 & 0.06 & 0 & 0.07 & 1.94 & 1.74 \\
\hline Sep & 0 & 0.14 & 0 & 0.2 & 0.3 & 0.34 & 0 & 0.12 & 0 & 0.13 & 2.66 & 2.22 \\
\hline Oct & 0.01 & 0.1 & 0.14 & 0.34 & 0.49 & 0.44 & -0.01 & 0.09 & 0 & 0.1 & 3.73 & 2.96 \\
\hline Nov & 0.2 & 0.25 & 0.38 & 0.46 & 0.27 & 0.27 & 0.18 & 0.23 & 0.21 & 0.26 & 4.61 & 3.97 \\
\hline Dec & 0.14 & 0.16 & 0.19 & 0.23 & 0.22 & 0.21 & 0.09 & 0.12 & 0.11 & 0.13 & 4.26 & 3.8 \\
\hline
\end{tabular}

Table 3. Statistical evaluation of HE and COMB in 2009.

\begin{tabular}{|c|c|c|c|c|c|c|c|c|c|c|c|c|}
\hline & \multicolumn{2}{|c|}{$\begin{array}{l}\text { Correlation } \\
\text { Coefficient }\end{array}$} & \multicolumn{2}{|c|}{ POD } & \multicolumn{2}{|c|}{ FAR } & \multicolumn{2}{|c|}{$\begin{array}{c}\text { Heidke Skill } \\
\text { Score }\end{array}$} & \multicolumn{2}{|c|}{$\begin{array}{c}\text { Hanssen Kuiper } \\
\text { Discriminant }\end{array}$} & \multicolumn{2}{|c|}{$\begin{array}{l}\text { Mean Abs } \\
\text { Error }\end{array}$} \\
\hline & $\mathrm{HE}$ & Comb & $\mathrm{HE}$ & Comb & $\mathrm{HE}$ & Comb & $\mathrm{HE}$ & Comb & $\mathrm{HE}$ & Comb & $\mathrm{HE}$ & Comb \\
\hline Jan & 0.25 & 0.28 & 0.36 & 0.44 & 0.14 & 0.19 & 0.18 & 0.2 & 0.23 & 0.26 & 5.82 & 4.97 \\
\hline Feb & 0.34 & 0.35 & 0.43 & 0.48 & 0.14 & 0.13 & 0.19 & 0.22 & 0.25 & 0.28 & 5.87 & 5.16 \\
\hline Mar & 0.04 & 0.06 & 0.16 & 0.19 & 0.39 & 0.37 & 0.05 & 0.06 & 0.06 & 0.07 & 3.08 & 2.91 \\
\hline Apr & 0.02 & 0.09 & 0.07 & 0.17 & 0.41 & 0.33 & 0.01 & 0.06 & 0.01 & 0.07 & 2.57 & 2.36 \\
\hline May & 0.04 & 0.11 & 0.19 & 0.26 & 0.42 & 0.3 & 0.06 & 0.12 & 0.07 & 0.13 & 2.46 & 1.95 \\
\hline Jun & 0.09 & 0.19 & 0.28 & 0.36 & 0.52 & 0.37 & 0.06 & 0.13 & 0.07 & 0.14 & 4.4 & 3 \\
\hline Jul & 0.01 & 0.09 & 0.07 & 0.16 & 0.61 & 0.41 & 0.01 & 0.06 & 0.01 & 0.06 & 2.77 & 2.16 \\
\hline Aug & 0.07 & 0.13 & 0.08 & 0.17 & 0.38 & 0.42 & 0.03 & 0.06 & 0.04 & 0.07 & 2 & 1.6 \\
\hline Sep & -0.02 & 0.18 & 0.09 & 0.35 & 0.46 & 0.31 & 0 & 0.18 & 0.01 & 0.18 & 2.79 & 2.15 \\
\hline Oct & 0.06 & 0.11 & 0.38 & 0.47 & 0.3 & 0.29 & 0.12 & 0.19 & 0.14 & 0.21 & 6.01 & 4.04 \\
\hline Nov & 0.05 & 0.14 & 0.27 & 0.4 & 0.41 & 0.36 & 0.05 & 0.13 & 0.06 & 0.15 & 4.83 & 4.17 \\
\hline Dec & 0.05 & 0.09 & 0.3 & 0.41 & 0.32 & 0.29 & 0.06 & 0.12 & 0.08 & 0.15 & 5.89 & 4.95 \\
\hline
\end{tabular}

measured by the gauges (bottom right). The statistics for this day (Fig. 12) shows that the COMB is performing better than the HE in all accounts. The MAE of the COMB is lower, and the rain rate of the COMB $\left(3.3 \mathrm{~mm} \mathrm{day}^{-1}\right)$ is closer to the rain rate of the gauges $\left(3.7 \mathrm{~mm} \mathrm{day}^{-1}\right)$.

\subsubsection{Example 2: 17-18 June 2008}

From the winter time example (Figs. 13 and 14) it is clear that the stratiform rainfall produced by the Unified Model (top left) captures the rainfall on the east coast and also the precipitation associated with the frontal passage over the central parts of the country. The HE (top right) missed the rainfall on the east coast of South Africa and over estimated the convection over the northern interior. In the COMB (bottom left), the stratiform precipitation along the east coast is evident as well as the convection captured by the HE, but bias-corrected to be more realistic. The combined field correlates well with the rain gauges (bottom right) in aerial extent as well as intensity.

Figures 15 and 16 show the statistics for these two days. The correlation coefficients for both days were negative using the $\mathrm{HE}$ on its own, but increase significantly using the COMB. The rain rate of the COMB is closer to the rain rate of the gauges on the 17th and matches the rain rate of the gauges perfectly on the 18th. In both cases the MAE is less when using the COMB. 


\subsubsection{Example 3: 12 July 2009}

Figure 17 shows that the UM stratiform field (top left) captured the rainfall along the southwestern coast well, the HE (top right) only captured some convective activity outside the rain gauge network, while the COMB (bottom left) was much closer to the rain gauge measurements (bottom right). In Fig. 18 the statistical evaluation of this day is shown. The correlation coefficient is negative for the HE along and more than 0.69 for COMB. The p-score for a correlation of 0.68 using 118 grid boxes with rain, is more than $99 \%$ significant. All the other scores are also better using the COMB.

From these examples it is clear that the improvement in the precipitation field not only eliminates the over estimation of the HE, but the stratiform events are also captured better. Advantages of the COMB rainfall field therefore include a better aerial coverage as well as more realistic rainfall totals. Providing such a hourly satellite based rainfall field as input to the SAFFG or in any other application for flash flooding would certainly be beneficial.

\section{Summary and conclusion}

In this article the applications of the satellite based precipitation measurement, namely the Hydroestimator (HE) for southern Africa were described. The HE is based on a single channel (IR10.8) from MSG and mainly uses the temperature of cloud tops to estimate precipitation rate every 15 minutes. Although improvements have been incorporated into the HE to avoid the possibility of getting rain from high level Cirrus clouds, but to include lower clouds which can cause precipitation, it is still considered to be mainly useful for convective precipitation. The HE has been available in southern Africa since the end of 2007. Shortcomings of the HE include the over estimation of precipitation amounts and the underestimation or missing of some stratiform events.

For any flood of flash flood warning system such as the SAFFG hourly accumulations of both radar rainfall and satellite based rainfall should be used. Unfortunately radars do not cover the entire South Africa and are also very scarce in the rest of Africa. The quality of satellite based precipitation estimations for South and southern Africa are crucial to ensure the accuracy of flood and/or flash flood warnings. In order to provide a more accurate and more comprehensive satellite precipitation based input field, a new combination product was developed. The new product aims to combine the strengths of the HE and the stratiform precipitation field from the Unified Model. The respective bias corrections of the HE as well as the UM stratiform field were determined over a two year period and these bias corrected products were combined into a new precipitation estimation field. The combined product was closer to the rain gauge measurements for daily accumulations of rainfall fields in 2008 and 2009. A few daily cases were shown to highlight the advantages of the new product. Future work will include adding all new available data to the data set in order to update the bias corrections. It is envisaged that this product will add value to flood and flash flood warnings in South Africa (using the SAFFG) and southern Africa (SARFFG).

Acknowledgements. I would like to thank Marianne Koenig for her role in implementing the local version of the Hydroestimator in South Africa in 2007. I am also acknowledging Deon Terblanche who contributed with innovative ideas to this work. I am grateful to the reviewers and editors for constructive comments to improve this document.

Edited by: S. Attinger

\section{References}

De Coning, E., Terblanche, D. E., and George, G.: Short range forecasting and nowcasting at the South African Weather Service using the newly acquired S-band radar systems, Meteorological Technology, International, UK, 120-123, 2010.

IPCC: Report on global warming - Localizing a global story, http://www.ipccinfo.com/extreme.php\#April6 (last access: 20 July 2009), 2007.

Kondragunta, C.: Quantitative Precipitation Estimation in the National Weather Service, NOAA's Water Resources Information, Office of Systems Development, NOAA/NESDIS, 13 March 2007, George Washington University, DC, http:// www.gwu.edu/ $\sim$ spi/assets/docs/Chandra_Kondragunta-NOAA' s\%20Water\%20Resources\%20Information.pdf (last access: 20 July 2009), 2007.

Kruger, A. C.: Climate of South Africa, Precipitation, Report No. WS47, South African Weather Service, Pretoria, South Africa, 41 pp., 2007.

Kuligowski, R. J., Qiu, S., Scofield, R. A. and Gruber, A.: The NESDIS QPE verification program in: Preprints, 11th Conf. on Satellite Meteorology and Oceanography, Am. Meteorol. Soc., Madison, WI, 383-384, 2001.

Kuligowski, R. J., Scofield, R. A., and Davenport, J. C.: The Hydro-Nowcaster: Recent improvements and future plans, in: World Weather Watch Research Programme International Symposium on Nowcasting and Very Short Range Forecasting, 59 September 2005, Toulouse, France, available at: www.meteo. fr/cic/wsn05/resumes_longs/5.15-203.pdf (last access: November 2010), 2005.

MSG-2 successfully launched: http://www.eumetsat.int/Home/ Main/News/Press_Releases/005023?l=en, (last access: 20 July 2009), 2005.

Poolman, E. R.: Implementing a new flash flood warning system for South Africa, SAWS Internal Report, available at South African Weather Service, Pretoria, South Africa, 2010.

Poolman, E. R., Chikoore, H., and Lucio, F.: Public benefits of the Severe Weather Forecasting Demonstration Project in south-eastern Africa, WMO Newsletter MeteoWorld, December 2008, available at: http://www.wmo.int/pages/publications/ meteoworld/archive/dec08/index_en.html (last access: November 2010), 2008. 
Scofield, R. A.: Comments on: "A quantitative assessment of the NESDIS Auto-Estimator", Weather Forecast., 16, 277-278, 2001.

Scofield, R. A. and Kuligowski, R. J.: Status and outlook of operational satellite precipitation algorithms for extreme-precipitation events, Weather Forecast., 18, 1037-1051, 2003.

STAR Satellite Rainfall Estimates: http://www.star.nesdis.noaa. gov/smcd/emb/ff/index.php, last access: 22 June, 2010.

Vicente, G. A., Scofield, R. A., and Mentzel, W. P.: The operational GOES infrared rainfall estimation technique, B. Am. Meteorol. Soc., 79, 1883-1898, 1998.
Vicente, G. A., Davenport, J. C., and Scofield, R. A.: The role of orographic and parallax corrections on real time high resolution satellite rainfall rate distribution, Int. J. Remote Sens., 23(2), 221-230, 2002.

Wilks, D. S.: Statistical Methods in Atmospheric Sciences, 2nd edition, Elsevier Science \& Technology Books, ISBN13: 9780127519661,627 pp., 2005. 